Recibido: julio de 2015

DOI:

http://dx.doi.org/I0.15332/rev.m.v|2il.1923
Aprobado: septiembre de 2015

\section{EL FUERTE DE SAN LORENZO DEL PUNTAL (CÁDIZ) Y EL FUERTE DE SAN FERNANDO DE BOCACHICA (CARTAGENA DE INDIAS): UNA VISIÓN COMPARADA*}

\author{
Gabriel Granado Castro** - Universidad de Sevilla, España \\ Hugo Aragón Barreto*** - Universidad Nacional de Colombia, sede Manizales, Colombia \\ Jorge Galindo Díaz **** - Universidad Nacional de Colombia, sede Manizales, Colombia
}

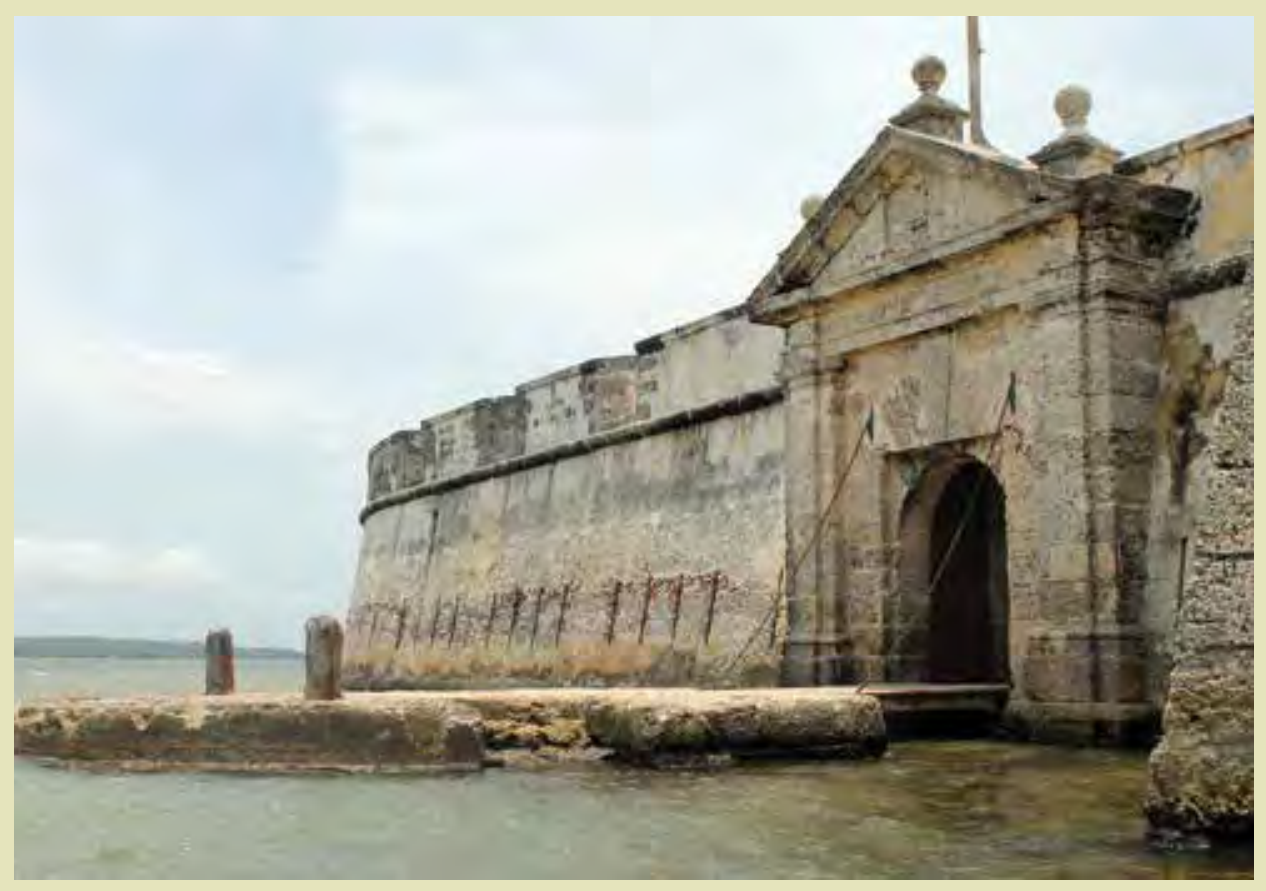

Fernando de Bocachica.

Fuente: Jorge Galindo, 2015.

* Este artículo es producto parcial de la investigación titulada "Los orígenes de la ingeniería en Colombia: la labor técnica de Ignacio de Sala y Antonio de Arévalo durante el siglo XVIII" (Código 28576), financiada por la Universidad Nacional de Colombia, sede Manizales.

** Arquitecto y Doctor en Arquitectura. Profesor Titular del Departamento de Ingeniería Gráfica y Cartográfica de la Universidad de Sevilla. ggranado@ us.es

*** Arquitecto por la Escuela de Arquitectura y Urbanismo de la Universidad Nacional de Colombia, sede Manizales. Auxiliar de investigación. haaragonb@unal.edu.co

**** Arquitecto y Doctor en Arquitectura. Profesor Titular de la Escuela de Arquitectura y Urbanismo de la Universidad Nacional de Colombia, sede Manizales. jagalindod@unal.edu.co

\section{RESUMEN}

A través de un estudio comparativo de dos fortificaciones similares en sus características geométricas y defensivas, este artículo ofrece una descripción de cada una desde una narrativa histórica. De modo que se especifica de qué forma los procesos de transformación y adaptación de edificios se dieron continuamente, como si se tratase de un proyecto único; lejos del modelo tradicional que asume las fortificaciones americanas como una simple adaptación de aquellos construidos en España.

\section{PALABRAS CLAVE}

Cádiz, Cartagena de Indias, Ignacio Sala, fortificaciones. 


\section{THE FORT OF SAN LORENZO DEL PUNTAL (CÁDIZ) AND THE FORT OF SAN FERNANDO DE BOCACHICA (CARTAGENA DE INDIAS): A COMPARATIVE VIEW}

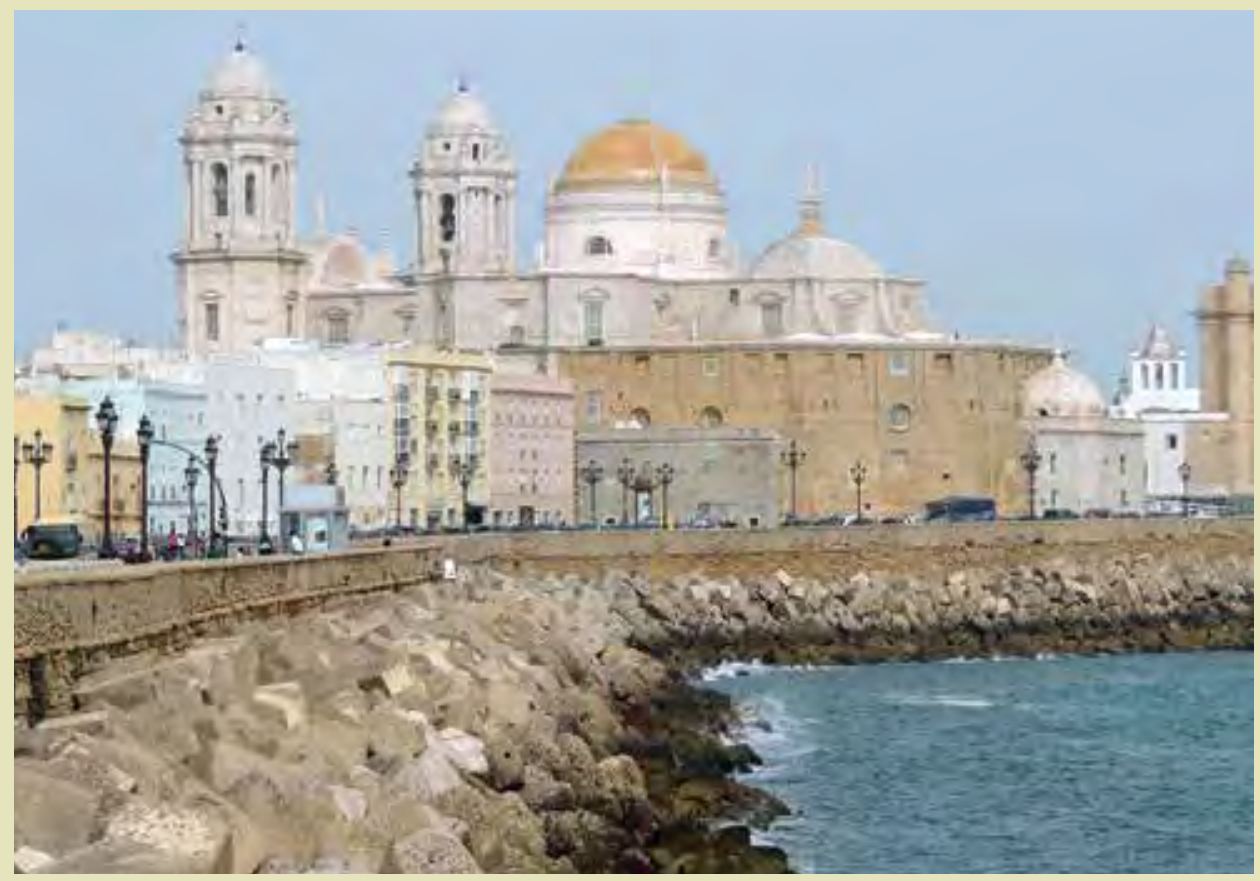

Vista del puerto de Cádiz desde sus murallas. Fuente: Jorge Galindo, 2015.

\section{ABSTRACT}

Through a comparative study of two fortifications, both similar in geometric and defensive characteristics, this paper gives a description of each of them from a historical narrative. Thus, it is specified how the processes of transformation and adaptation of buildings occurred continuously, as if it were a single project, away from the traditional model that assumes American fortifications as a simple adaptation of those that were built in Spain.

\section{KEYWORDS}

Cádiz, Cartagena de Indias, Ignacio Sala, fortifications. 


\section{INTRODUCCIÓN}

En la ciudad española de Cádiz, puerto de embarque de muchos de los ingenieros militares que tendrían a América como destino, existe desde el siglo XVI el fuerte de San Lorenzo del Puntal; caracterizado geométricamente por tener una planta ovalada dotada de un frente curvo que mira al mar y dos semibaluartes con flanco y foso orientados hacia el frente de tierra. Su posición estratégica está claramente vinculada al fuerte de Matagorda, de tal manera que entre ambos se podía producir un fuego cruzado para defender la entrada a la bahía.

Por su parte, en la ciudad americana de Cartagena de Indias (actual Colombia) se levantó desde mediados del siglo XVIII el fuerte de San Fernando de Bocachica, con características morfológicas similares al de Cádiz, en tanto adoptó una planta de forma elíptica con un frente curvo orientado hacia el mar, que mira a la batería de San José, mientras dos baluartes dirigen sus puntas al frente de tierra.

Ambos edificios comparten no solo semejanzas geométricas y defensivas, sino también la presencia del ingeniero militar Ignacio Sala, traductor al castellano de las obras de Vauban, y quien trabajaría en Cádiz entre 1730 y 1748, antes de ser enviado a América en calidad de Gobernador y Comandante General de Cartagena de Indias (Gutiérrez, 1991).

A continuación se presenta un relato de la génesis histórica de ambos fuertes; también se describen las particularidades arquitectónicas de cada edificio, con el fin de demostrar que estas no fueron el resultado de un simple proceso de aplicación de saberes desde el centro hacia la periferia, sino más bien un procedimiento en doble vía, en el cual cada ajuste espacial o constructivo se entendía como parte de un mismo constructo de mejora continua sobre las estructuras defensivas.

Desde el punto de vista metodológico, la investigación que soporta este artículo emplea la comparación morfológica como punto de partida, en virtud de la posibilidad de acceder a fuentes cartográficas que dan cuenta de aspectos dimensionales y geométricos datados en el tiempo en cada uno de los fuertes.

\section{EL FUERTE DE SAN LORENZO DEL PUNTAL}

Situado en una de las zonas más estratégicas de la bahía de Cádiz, justo en la entrada a la misma, produciendo un estrechamiento del canal de acceso; este lugar despertó tempranamente la necesidad de los gaditanos de fortificarlo y convertirlo en uno de los puntos claves del sistema defensivo, capaz de protegerlos de las constantes amenazas extranjeras.

La Figura I permite apreciar una vista general de la ciudad de Cádiz y su bahía a finales del siglo XVI. En ella se advierte el casco urbano amurallado (A) y el canal de acceso (B), salvaguardado por los fuertes de El Puntal (C) y Matagorda (D) que protegían el acceso a la bahía, una de las zonas de más fácil acceso desde el mar; tal como se demostró en el fatídico ataque angloholandés de 1596.

\section{ORÍGENES}

Durante todo el siglo XVI, las peticiones por parte de los regentes de la ciudad, respecto la necesidad de reforzar las defensas de la misma, habían sido constantes. La ciudad disponía tan solo de un pequeño muro de tierra y un castillo en estado ruinoso (Fernández, 1973). 
Entre estas necesidades, se consideraba importante la entrada a la Bahía, con sus dos extremos: Matagorda y San Lorenzo del Puntal. A pesar de ello, los primeros esfuerzos económicos fueron destinados a la defensa del territorio urbano de la propia ciudad, dejando la bahía para futuras dotaciones.

En la segunda mitad del siglo XVI empezaron a trabajar diversos ingenieros italianos en el sistema defensivo de Cádiz, quienes introdujeron las innovaciones propias del sistema de frentes abaluartados. El primero de ellos, Giovan Battista Calvi, consideró en 1557 la necesidad perentoria de edificar tres baluartes en la parte de la ciudad que se orientaban

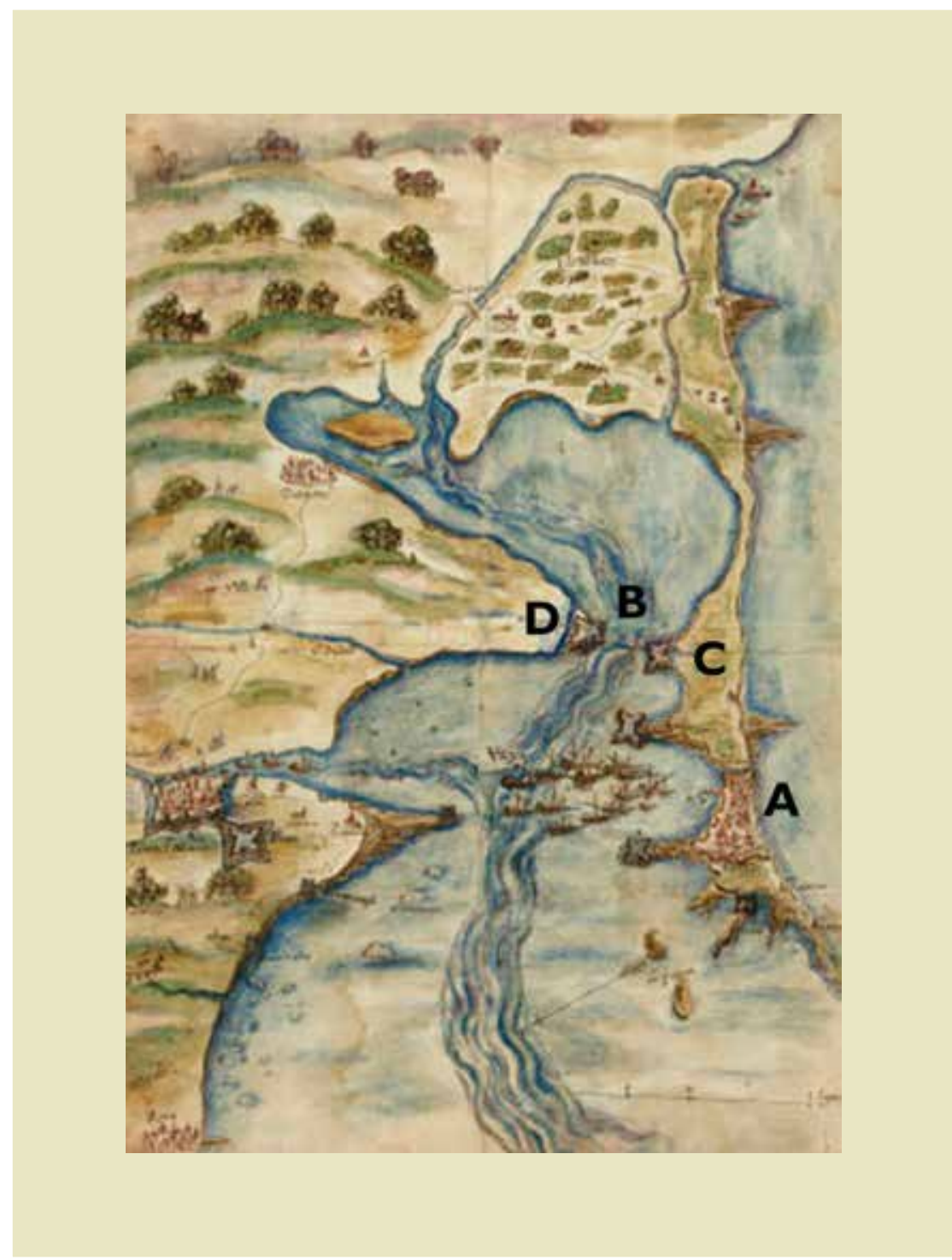

Figura I. Planta General de la ciudad de Cádiz y su bahía. Finales del siglo XVI.

Fuente: Ministerio de Cultura, Institut Cartogràfic de Catalunya, Cartoteca, RM.24669. 
hacia la bahía, si bien para los proyectados en el arrecife, en el que se incluía el fuerte del Puntal, no existía dotación económica (Martínez, 2002). A Calvi le sucedieron Giacomo Fratino y Vespasiano Gonzaga, quienes tampoco pudieron dar comienzo al fuerte del Puntal, empleando los escasos caudales suministrados en la defensa de la ciudad, fundamentalmente en el frente de tierra y de la bahía (Garófano, 20I2).

No será hasta la llegada de Tiburcio Spanochi a Cádiz en 1587 cuando se retome la posibilidad de edificar un fuerte en el sitio de El Puntal. De hecho, era considerada una de las actuaciones prioritarias para el ingeniero italiano (Garófano, 2012). Las obras comenzaron en 1588 y fueron terminadas en mayo de 1589 . Se trató de un fuerte de pequeñas dimensiones, con escasa altura, cinco piezas de artillería y cuatro aposentos, tal como se aprecia en la Figura 2 en el plano de 1598, donde se distinguen, además, dos baluartes dispuestos diagonalmente sobre la planta, en estos se proyectan lanzamientos de balas de cañón cuyo alcance permite llegar hasta la península de Matagorda, al otro lado del estrecho.En la misma Figura 2, se insinúan muros en piedra como solución constructiva. En 1594 se añadieron tres espacios más y un cuerpo de guardia (Fernández, 1973). En realidad, no se pensaba que esta primitiva defensa pudiera cumplir su misión de impedir la entrada de naves a la bahía.

\section{SU RECONSTRUCCIÓN TRAS EL ATAQUE DE I596}

Las carencias existentes en el sistema defensivo de Cádiz se pusieron de manifiesto cuando el 30 de junio de 1596 una gran flota de buques ingleses y holandeses entró en la bahía y, sin apenas resistencia, consiguió entrar a la ciudad, arrasándola por completo (Abreu, 1866). Precisamente el desembarco de las tropas angloholandesas se realizó en las inmediaciones del fuerte de El Puntal, no ofreciendo dicha pieza resistencia alguna (De la Concepción, 2002), a tal punto que el fuerte fue tomado y destruido por las tropas enemigas.

Una vez la coalición angloholandesa abandonó la ciudad, la corona española estudió la recomposición de la ciudad y sus defensas. Para tal cometido, Felipe II envió a Cádiz a Cristóbal de Rojas, quien ya había trabajado en la ciudad como maestro de obras; ahora él era enviado en calidad de ingeniero. Con respecto al fuerte de El Puntal, se decidió deshacerlo y mejorarlo en el mismo paraje, pero adelantándolo en el mar (Mariátegui, 1985).

En todas las deliberaciones que se realizaron sobre la forma de fortificar la ciudad tras el saqueo de I596, los fuertes de El Puntal y Matagorda cobraban una importancia capital en el control de la bahía.

Aunque en octubre de 1597 Felipe II decidió aprobar los proyectos de fortificación de la ciudad, entre los que se incluía la reconstrucción del fuerte de San Lorenzo del Puntal, todavía en 1608 Cristóbal de Rojas no había podido dar inicio al mismo por falta de caudales, y por estar ocupado en la construcción del Castillo de Santa Catalina y la fortificación de los baluartes en el frente de tierra. Tan solo había sido posible cortar un millar de pinos para hacer estacadas para los cimientos (Fernández, 1973).

En enero de 1612 Cristóbal de Rojas informaba al Rey que la cimentación del fuerte de EI Puntal iba firme y muy adelantada, pero que necesitaba una mayor dotación económica para que se terminara (Mariátegui, 1985). La obra del fuerte prosiguió de manera discontinua durante los siguientes años. En 1616, muerto ya Cristóbal de Rojas, solo estaban levantados los cimientos; a finales de dicho año se realizaron reformas en el proyecto original y se corrigieron defectos que habían sido detectados en el proyecto del castillo de Santa Catalina. A partir de este momento, las obras del fuerte fueron asumidas por el juez de comisión de las torres atalayas de Andalucía, Juan de la Fuente Hurtado (Fernández, 1973). 


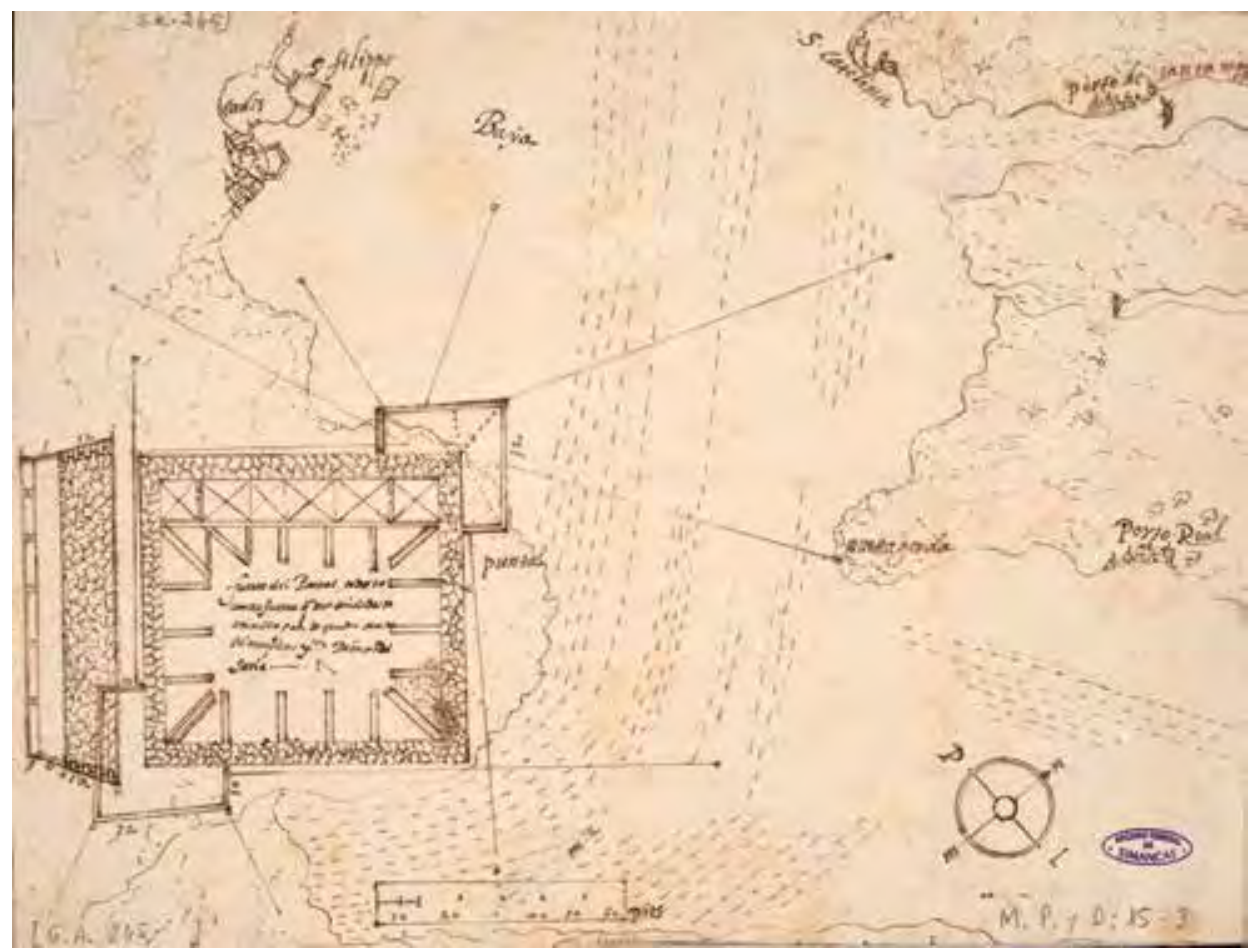

En 1623 , el fuerte se encontraba terminado y listo para defender la ciudad, como lo demostró durante el nuevo ataque anglo-holandés (1625). El aspecto definitivo del fuerte de San Lorenzo del Puntal en el siglo XVII se puede observar en la Figura 3.

Aquí se destaca la traza de dos angulosos baluartes orientados hacia tierra firme $y$ un frente amplio hacia el mar, donde se buscaba obtener una máxima visibilidad. Las construcciones del interior no aparecen detalladas.

\section{LAS REFORMAS DE IGNACIO SALA}

A pesar de que el fuerte requería obras para su completa terminación, tales como la finalización de su talud y estrada cubierta, según informe de

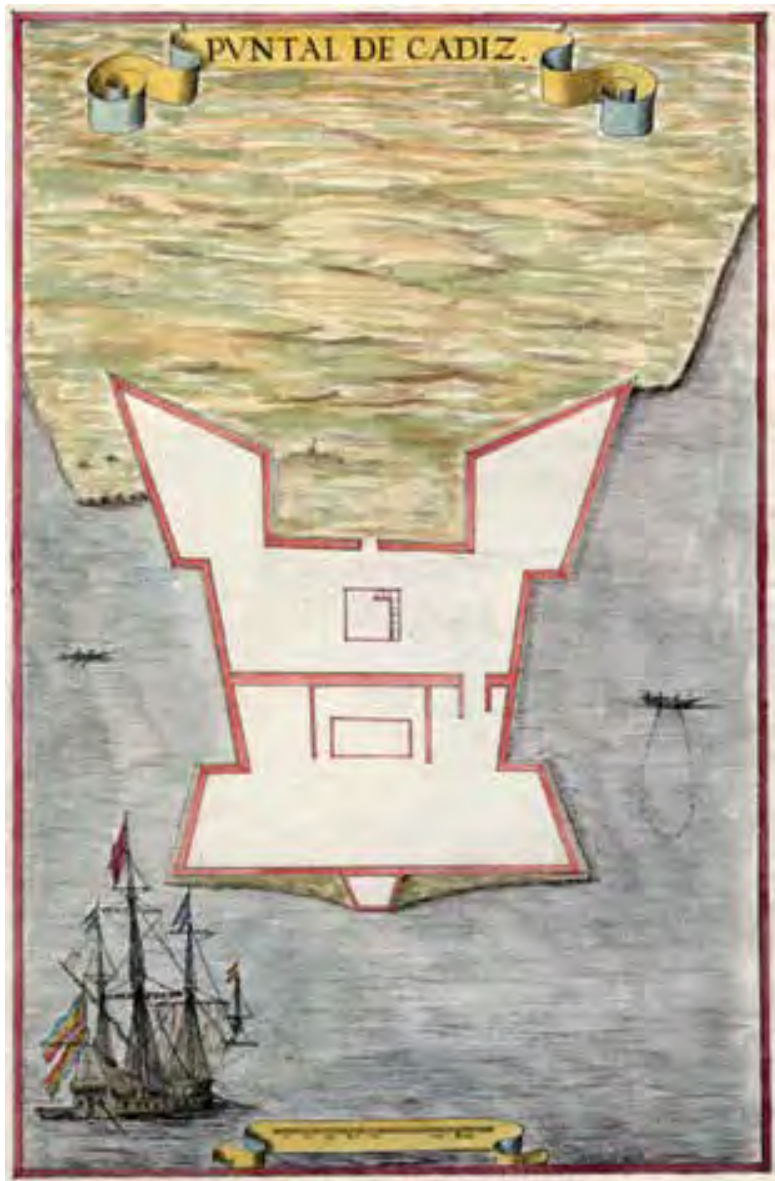

Figura 3. Planta del Fuerte de San Lorenzo del Puntal. Mediados del siglo XVII.

Fuente: Sánchez, Testón, Sánchez, 2004. Imágenes de un imperio perdido. El Atlas del Marqués de Heliche. Plantas de diferentes Plazas de España, Italia, Flandes y Las Indias. Badajoz: Presidencia de la Junta de Extremadura. 
Julio Román de Arellano de 1639 (Fernández, 1973), pocas fueron las intervenciones a las que fue sometido en todo lo que restó del siglo XVII.

No será hasta inicios del siglo XVIII, cuando fue creado el cuerpo de ingenieros militares tras la instauración borbónica en la monarquía, cuando se replanteó nuevamente el estado de las defensas de la ciudad de Cádiz y, entre ellas, la consolidación del fuerte de San Lorenzo del Puntal.

En esa transformación de la ciudad de Cádiz, como plaza fuerte del siglo XVIII, tiene un rol fundamental lgnacio Sala, uno de los mejores ingenieros militares españoles de la época y quien llegó a Cádiz en 1717; participó casi en la totalidad de las obras que se hicieron en la ciudad hasta que en 1749 fue trasladado a Cartagena de Indias para dirigir la reconstrucción de sus defensas tras el ataque de Vernon. Por más de 30 años, Sala estuvo en Cádiz y dirigió todas las obras de fortificación, permitiendo que la ciudad se convirtiera en uno de los puertos más seguros del país.

Las obras de remodelación en el fuerte de San Lorenzo del Puntal comenzaron en I 724 y se prolongaron por seis años más; se modificó su frente de tierra mediante la construcción de una nueva batería, que si bien no llegaba a prefigurar la cortina curva que ostentará años después, sí destacaba la importancia de este flanco en su labor defensiva de la bahía de Cádiz. La Figura 4, que contiene un plano fechado en 1738 y delineado probablemente por el propio Ignacio Sala, permite apreciar la planta con la configuración antes señalada y, de manera especial, una sección que muestra el muro frente al mar y el manejo del terreno inclinado denominado glacis.

En cualquier caso, la labor del ingeniero Ignacio de Sala Garrigo (I686 - I754), durante los 22 años que pasó en el puerto de Cádiz, no se limitó a las obras del fuerte de El Puntal; desde 1728 (dos años después de su llegada a la ciudad), se dedicó a la elaboración de un ambicioso proyecto de reforma y reconstrucción de todo el sistema defensivo de la ciudad y de manera especial de la llamada "Puerta de Tierra", en el extremo de la ciudad, así como del conjunto de baluartes y fortalezas dispuestos en torno a la ciudad. De acuerdo con Cruz (20I3), no hay datos acerca de su formación como ingeniero, aunque se sabe que participó como ingeniero voluntario en Cataluña durante la Guerra de Sucesión, tras lo cual entró a formar parte del Cuerpo de Ingenieros bajo la dirección de Jorge Próspero de Verboom, siendo destinado a las plazas de Lérida y Barcelona.

Figura 4. Planta y perfil del castillo del Puntal, por Ignacio Sala, 1738.

Fuente: Ministerio de Cultura, Archivo General de Simancas, Secretaría de Guerra, 03246.
A su labor práctica, se sumaron la redacción y publicación de varios tratados de ingeniería militar, entre los que se destaca la traducción de la obra de Vauban "Tratado de las defensas de las Plazas de M. Vauban", publicado en 1743.

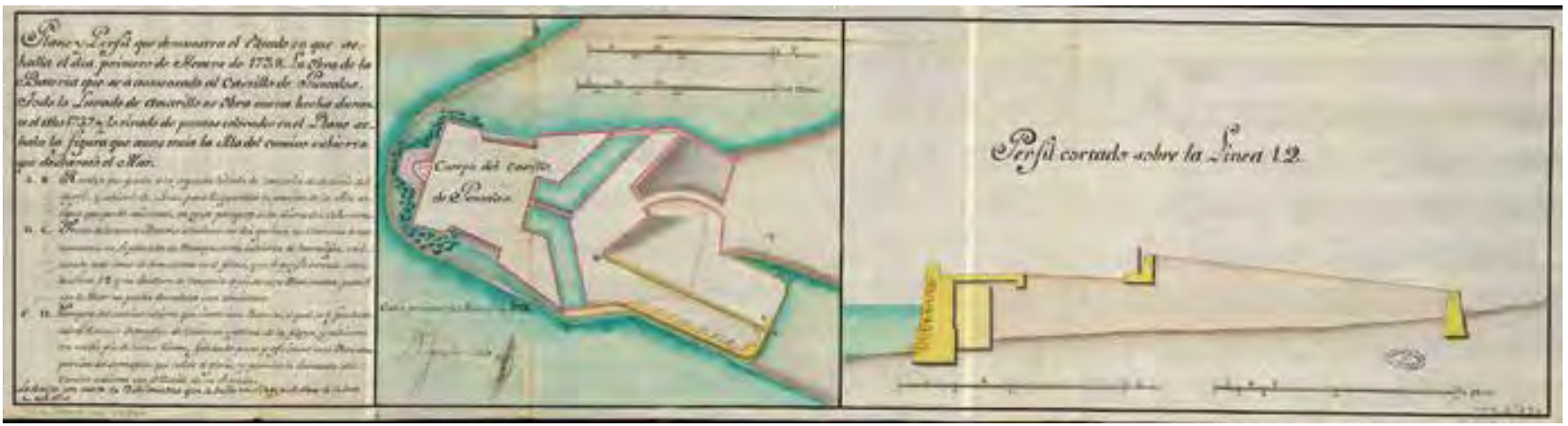




\section{EL FUERTE DE SAN FERNANDO DE BOCACHICA EN CARTAGENA DE INDIAS}

En el lugar que hoy ocupa el fuerte de San Fernando (defendiendo el paso por el canal de Bocachica, sobre la isla de Tierrabomba) se levantó entre 1646 y 1649 el castillo de San Luis de Bocachica, con traza del ingeniero Juan de Somovilla y construido bajo la dirección técnica de Juan Bautista Antonelli (Paradiso, Galassi y Benedetti, 20 I3). En 1697 el edificio fue destrozado por el ataque de Pointis y posteriormente reconstruido por Juan de Herrera y Sotomayor en 1715, aunque las obras no estaban terminadas para cuando el sitio fue atacado nuevamente, esta vez por Vernon en I74I.

Con la llegada de Ignacio Sala a Cartagena de Indias, en I749, una de sus primeras decisiones fue determinar el emplazamiento y la geometría de un nuevo fuerte capaz de reemplazar al de San Luis. Para entonces, existía una propuesta formulada con anterioridad por el ingeniero Juan Bautista Mac Evan, según la cual los frentes del nuevo edificio debían situarse de manera paralela al acceso para que así la batería pudiese apuntar al costado de los barcos enemigos que entraran por el canal. Contrariamente, Sala tenía la idea de disponer el fuerte con su frente hacia el mar para que los barcos fuesen abatidos por la proa (Cruz, 2013).

Ambas propuestas, enfrentadas de manera radical, fueron enviadas a la Corona, en donde fue escogida la de Mac Evan, quien, para entonces, ya había fallecido. Su propuesta se inscribía en una planta elíptica que generaba una cortina circular enfrentada a la batería de San José (rediseñada esta sí por el propio Sala en I75I), con dos amplios baluartes que apuntaban hacia tierra firme.

\section{LA CONSTRUCCIÓN DEL FUERTE DE SAN FERNANDO}

Los primeros trabajos de construcción del fuerte americano tuvieron lugar entre 1753 y 1760, bajo la dirección del ingeniero militar Antonio de Arévalo, quien seguiría con fidelidad los diseños de Mac Evan. Un plano de 1750, reproducido en la Figura 5 y firmado por este último, permite ver las características del emplazamiento, así como la distribución interior de los espacios e incluso su relación con el fuerte de San José en el lado opuesto del estrecho.

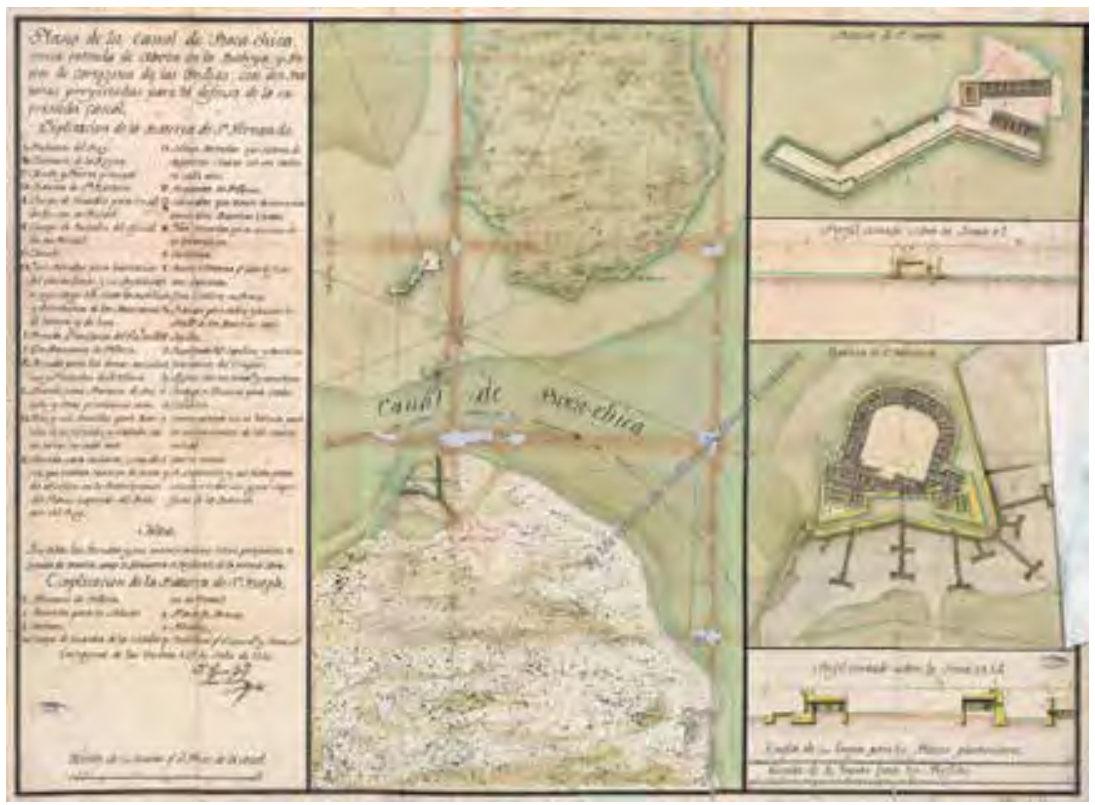

Figura 5. Plan del canal de Bocachica, con detalles del fuerte de San Fernando y la batería de San José, por Juan Bautista Mac Evan, 1752.

Fuente: Ministerio de Cultura, Archivo General de Simancas, Secretaría de Guerra, I I05 I. 
Figura 6. Vista actual del patio y rampa del fuerte de San Fernando de Bocachica. Fuente: Jorge Galindo, 2015
En el plano, se aprecia en color rojo la traza del viejo castillo de San Luis; de planta cuadrada con cuatro baluartes en las esquinas y asentado sobre tierra firme. Por su parte, el castillo de San Fernando se sitúa en el borde de la costa, separándose de tierra firme mediante un foso húmedo y construyendo un glacis en torno a él. Dos baluartes miran hacia el frente de tierra y una cortina curva mira hacia el estrecho y, por lo tanto, hacia el fuerte de San José.

Desde el punto de vista de su distribución espacial, el edificio se organiza efectivamente alrededor de un gran espacio libre en forma de $U$, de aproximadamente 40 por $60 \mathrm{~m}$, desde el cual se puede acceder a todos los recintos, los cuales se cubren mediante bóvedas de arista. También desde el patio se eleva una rampa de carácter monumental que conduce a una terraza almenada, desde la cual se tiene una vista panorámica del entorno, tal como se observa en la Figura 6 que corresponde a una vista actual del edificio.

Las entradas al edificio son dos: la primera es desde el mar, de tal manera que sobre la cortina curva se levanta una imponente portada hecha en piedra dotada de un puente levadizo. La segunda entrada, más modesta, se sitúa en la parte de tierra firme a través de una pasarela que salva el foso.

Desde el aspecto material, el edificio se resuelve a partir de potentes muros perimetrales de carga hechos con bloques de piedra caliza, a veces mezclados con ladrillos y piedras más pequeñas. Morteros elaborados a partir de cal, puzolana, polvo de ladrillo y gutagamba (resina vegetal propia del sitio), también están presentes en las mamposterías (Campos, 2003).

\section{CAMBIOS POSTERIORES A SU CONSTRUCCIÓN}

Con posterioridad a su terminación, en 1760, el fuerte de San Fernando de Bocachica no ha sufrido alteraciones profundas en su espacialidad: el patio central, la rampa de acceso a la terraza y los salones interiores (divididos entre sí por los pesados muros de carga y pilares) se han conservado con unas pocas intervenciones de mantenimiento. Sus características morfológicas, su emplazamiento y sus virtudes técnico constructivas, permiten afirmar que el fuerte de Cartagena es todavía el claro resultado de más de 200 años de la experiencia de la fortificación defensiva hispanoamericana.

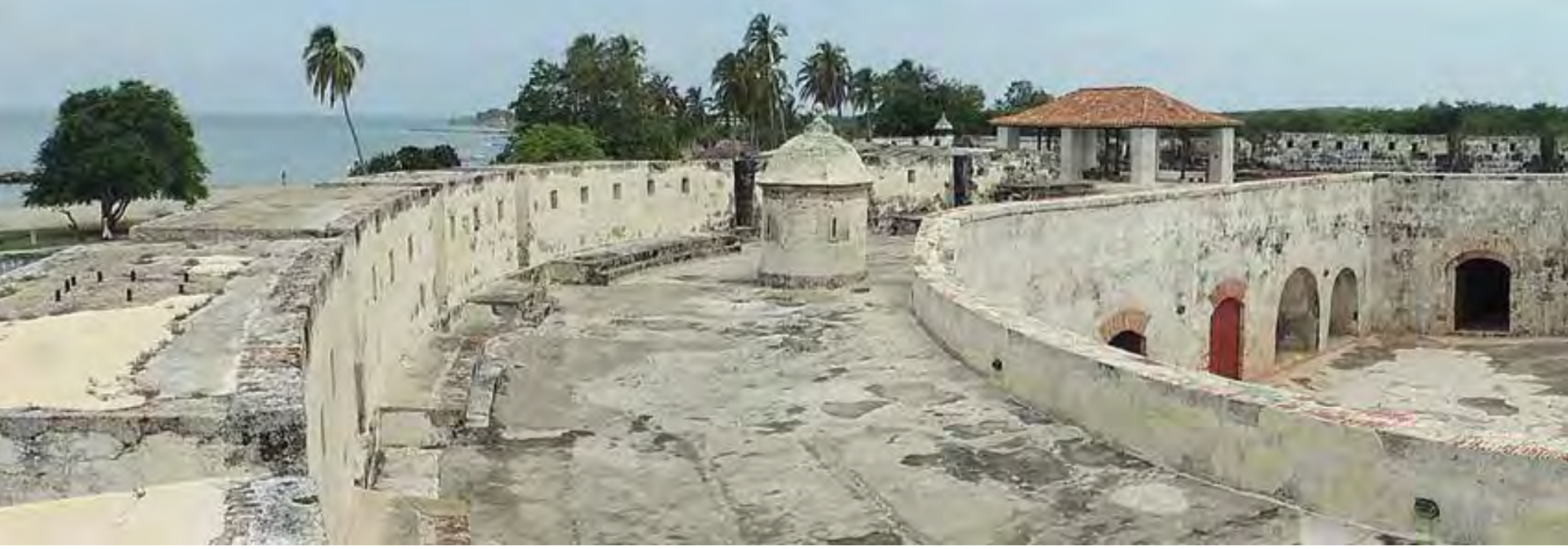


El edificio nunca fue atacado y durante buena parte del siglo XIX fue olvidado y abandonado; en 1958 se empezaron a dar las primeras acciones para su recuperación. Recientemente se han adelantado trabajos orientados a asegurar la estabilidad de sus cimentaciones, debilitadas por la acción del oleaje y de manera especial por los embates producidos por el agua a causa de la navegación de gran calado por el canal de Bocachica.

\section{SIMILITUDES ENTRE LOS FUERTES DE SAN LORENZO DE PUNTAL Y SAN FERNANDO DE BOCACHICA}

Si bien hasta finales del siglo XVIII los fuertes de El Puntal y San Fernando guardaban diferencias geométricas, sí tenían en su concepción varios aspectos comunes: (a) ambos casos eran producto de procesos de reconstrucción en donde el nuevo edificio se planteaba como una solución "mejorada" de lo existente; (b) las dos edificaciones tienen como objetivo principal la defensa del acceso a una bahía para lo cual deben dotarse de un frente de mar y resguardarse de posibles ataques que llegaran desde tierra mediante bastiones angulares que se proyectan desde el cuerpo principal separados a su vez mediante un foso de la tierra firme; (c) en los dos casos el fuerte está acompañado por una batería que desde el otro lado de su posición, acompaña mediante fuego cruzado su accionar ofensivo.

Adicionalmente, tanto en el fuerte de San Lorenzo del Puntal como en el de San Fernando de Bocachica se advierten similitudes de escala indicadas en la Figura 7; el primero es de mayor superficie y de dos pisos de altura, al menos en la actualidad.

En cuanto al enorme parecido del trazado en planta, es importante destacar que la actual forma del fuerte de San Lorenzo del Puntal es resultado de las transformaciones acontecidas entre 1862 y $I 863$ con el fin de recuperar el edificio luego del considerable deterioro sufrido por el fuerte tras su decisiva participación en la defensa de la ciudad durante el asedio napoleónico ( $18|0-18| 2)$. Esta remodelación cambió completamente su estructura y geometría, siendo la misma la que goza actualmente.

Si las reformas de Ignacio de Sala en el siglo XVIII se centraron en el frente de tierra, esta nueva remodelación cambiará la geometría del frente de mar, utilizando en el diseño de

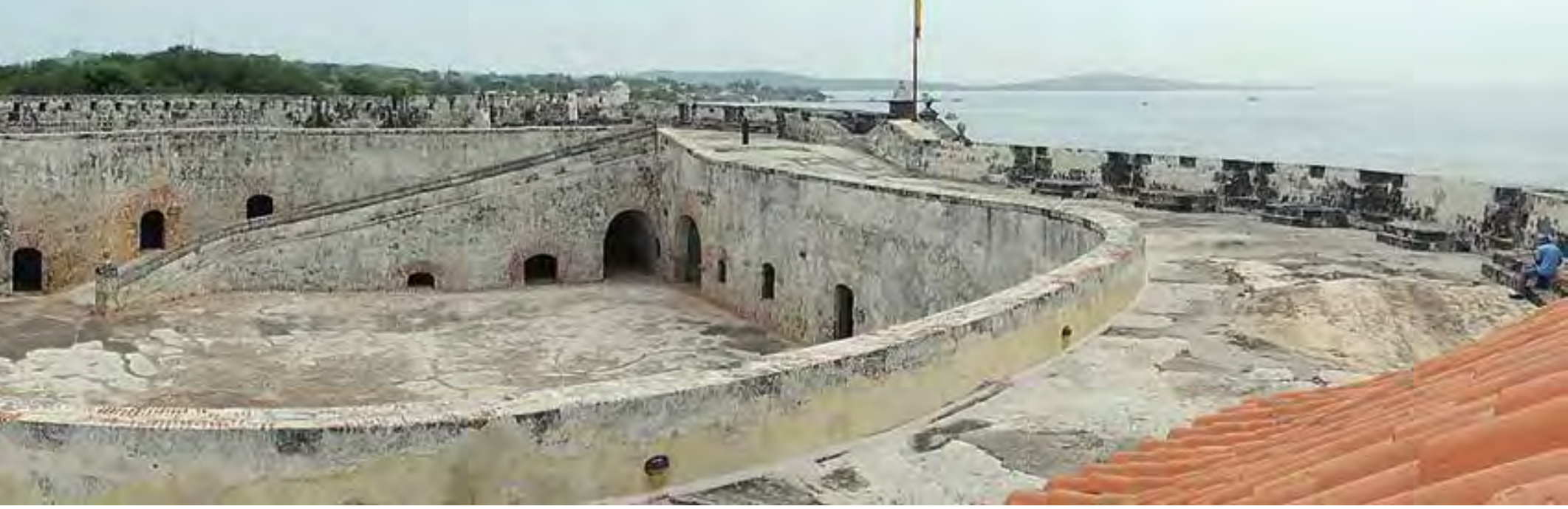


Figura 7. Vista comparada de los fuertes de San Lorenzo de Puntal (izquierda) y San Fernando de Bocachica (derecha), dibujados a la misma escala.

Fuente: Jorge Galindo, 2015

Figura 8. Planta, perfil y vista del castillo de $E$ Puntal, por Rafael Cerero, 1862

Fuente: Archivo General Militar, Madrid, plano CA- I/6. la planta, arcos de circunferencia tal como se advierte en la Figura 8 y dejando obsoleta la estructura abaluartada que había defendido su forma desde su construcción en el siglo XVI.

Tales actuaciones serán realizadas por el Ingeniero Brigadier del Cuerpo de Ingenieros del Ejército Español D. Rafael Cerero Sáenz ( 1834-1906). La solución adoptada emplea en el frente de mar una cortina continua, formada por varios tramos circulares con diferentes centros, similar a la que se empleó en las reformas realizadas por esas fechas en el castillo de San Sebastián y que sin duda también fueron adoptadas a partir del diseño de San Fernando de Bocachica.
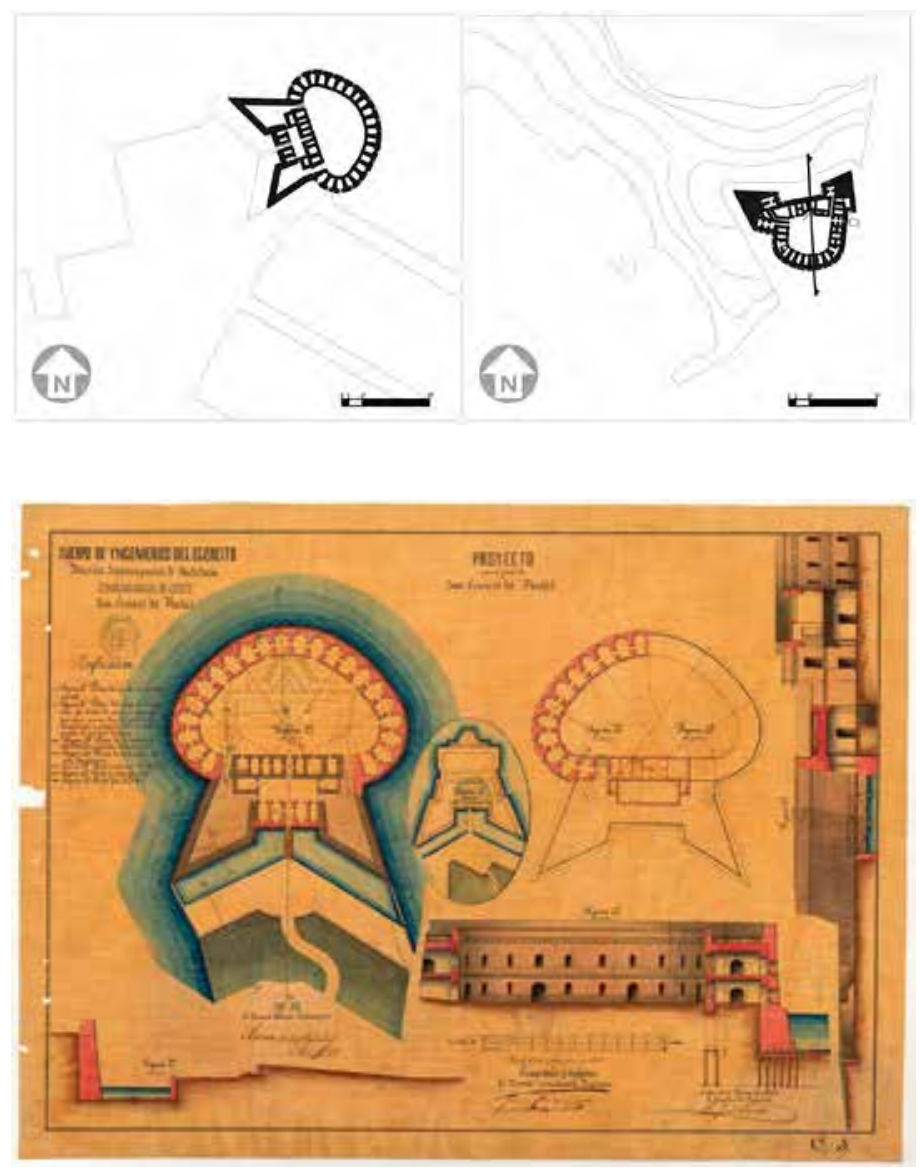

\section{CONCLUSIONES}

El breve estudio que se reseña en este artículo pretende demostrar la manera en que la experimentación tipológica y constructiva era una actividad inherente a la del ingeniero militar del siglo XVIII, a través de un proceso de ajustes continuos a las estructuras fortificadas en donde el trazado geométrico era considerado un punto de partida hacia el equilibrio entre forma y sistema defensivo. Vale la pena mencionar que el dimensionado de las partes de la fortificación, durante todo el siglo XVIII, estaba condicionado claramente por el alcance del armamento.

Como resultado de ese constante proceso de experimentación y ajuste, es posible afirmar que los avances que se dieron, tanto en Cádiz como en otras ciudades españolas, en 
materia defensiva y arquitectónica, sirvieron de referente a las transformaciones aplicadas en los territorios americanos dentro de un proceso de continuidad. De tal manera que los logros allí alcanzados, también contribuían a nuevos procesos de adaptación en la península ibérica. No se puede decir de manera tajante que en el siglo XVIII existió una única vía de transmisión de saberes: la de la península Ibérica hacia sus territorios de Ultramar. Por el contrario, ellos se alimentaron de experiencias en ambas orillas, tanto en el plano constructivo como en el geométrico-defensivo.

Con respecto a la labor técnica y militar de Ignacio de Sala, tanto en Cádiz como en Cartagena de Indias está aún por ser estudiada. En el caso que nos ocupa, se advierte una coherencia en sus propuestas defensivas, así como una enorme capacidad de comprender el conjunto de particularidades del territorio en el que debía adelantar sus proyectos. Y aunque Sala no apoyó la disposición que finalmente adoptó el fuerte de San Fernando de Bocachica, se destaca su papel en la reorganización defensiva de Cartagena de Indias y su capacidad organizativa y de gestión de las obras a su cargo.

\section{REFERENCIAS}

Abreu, F.P. de. (1866). Historia del Saqueo de Cádiz por los ingleses en 1596. Cádiz: Editorial Revista Médica.

Campos, D.P. (2003). Investigación del fuerte de San Fernando de Bocachica: una visión integral. Valencia: UPV.

Cruz, P. (20/3). El ingeniero militar Ignacio Sala, Gobernador y Comandante General de Cartagena de Indias. Noticias de su pase a Indias y de su labor en las defensas de la ciudad. Laboratorio de Arte, 25, 469-48I.

De la Concepción, F.J. (2002). Emporio de el Orbe Tomo Il. Cádiz: Servicio de Publicaciones de la Universidad de Cádiz y Ayuntamiento de Cádiz.

Fernández, V. (1973). Las defensas de Cádiz en la Edad Moderna. Sevilla: CSIC - Escuela de Estudios Hispanoamericanos.

Gutiérrez, R. (199I). Territorio y fortificación. Vauban, Fernández de Medrano, Ignacio Sala y Félix Prósperi. Influencia en España y América. Madrid: Ediciones Tuero.

Garófano, R. (2012). Cádiz Amurallada. Su registro fotográfico. Cádiz: Quorum Editores.

Mariátegui, E. (1985). El capitán Cristóbal de Rojas, ingeniero militar del siglo XVI. Madrid: Servicio de publicaciones del MOPU.

Martínez, D. (2002). Giovan Battista Calvi. Ingeniero de las fortificaciones de Carlos V y Felipe II (I552- I565). Barcelona: Ministerio de Defensa.

Paradiso, M., Galassi, S., Benedetti, S. (2013). Una contribución para conocer el fuerte de San Fernando de Bocachica, Cartagena de Indias, Colombia. Revista M, 2 (I0), I36-I 58.

Sánchez, R., Testón I., Sánchez C. M. (2004). Imágenes de un imperio perdido. El Atlas del Marqués de Heliche. Plantas de diferentes Plazas de España, Italia, Flandes y Las Indias. Badajoz: Presidencia de la Junta de Extremadura. 